\title{
New high-technology products for the treatment of haemophilia
}

\author{
S. W. PIPE, * J-M. SAINT-REMY† and C. E. WALSH $†$ \\ *Department of Pediatrics, University of Michigan, Ann Arbor, MI USA; †Center for Molecular and Vascular Biology, \\ University of Leuven, Leuven, Belgium; and $\ddagger$ Department of Medicine, Mount Sinai School of Medicine, New York, NY, \\ USA
}

Summary. This review will focus on new technologies in development that promise to lead to further advances in haemophilia therapeutics. There has been continued interest in the bioengineering of recombinant factor VIII (rFVIII) and factor IX (rFIX) with improved function to overcome some of the limitations in current treatment, the high costs of therapy and to increase availability to a broader world haemophilia population. Bioengineered forms of rFVIII, rFIX or alternative haemostatic molecules may ultimately have an impact on improving the efficacy of therapeutic strategies for the haemophilias by improving biosynthesis and secretion, functional activity, half-life and immunogenicity. Preventing and suppressing inhibitors to factor (F) VIII remain a challenge for both clinicians and scientists. Recent experiments have shown that it is possible to obtain anti-idiotypic antibodies with a number of desirable properties: (i) strong binding avidity to FVIII inhibitors; (ii) neutralization of inhibitory activity both in vitro and in vivo; (iii) cross-reactivity with antibodies from unrelated patients, and (iv) no interference with FVIII function. An alternative, although complementary approach, makes use of peptides derived from filamentous-phage random libraries. Mimotopes of FVIII can be obtained, which bind to the paratope of inhibitory activity and neutralize their activity both in vitro and in vivo. In this paper, we review advanced genetic strategies for haemophilia therapy. Until recently the traditional concept for gene transfer of inherited and acquired haematological diseases has been focused on how best to obtain stable insertion of a cDNA into a target-cell genome, allowing expression of a therapeutic protein. However, as gene-transfer vector systems continue to improve, the requirement for regulated gene transcription and hence regulated protein expression will become more critical. Inappropriate protein expression levels or expression of transferred cDNAs in non-intended cell types or tissues may lead to targetcell toxicity or activation of unwanted host immune responses. Regulated protein expression requires that the transferred gene be transferred with its own regulatory cassette that allows for gene transcription and translation approaching that of the normal gene in its endogenous context. New molecular techniques, in particular the use of RNA molecules, now allow for transcription of corrective genes that mimic the normal state.

Keywords: anti-idiotype antibodies, bioengineering, haemophilia, RNA repair

\section{Coagulation factors bioengineered for improved haemophilia therapeutics}

Current developments in mammalian cell-culture technology and recombinant protein expression have

Correspondence: Dr S. W. Pipe, Pediatrics and Communicable Diseases, University of Michigan, L2110 Women's Hospital, 1500 E. Medical Center Drive, Ann Arbor, MI 48109-0238, USA. Tel.: + 1734647 2893; fax: + 1734936 7083;

e-mail: ummdswp@med.umich.edu enabled the production of recombinant (r)FVIII and rFIX devoid of any human protein exposure during the cell culture fermenting process and in final formulation [1]. However, rFVIII/rFIX replacement remains a very expensive therapeutic, with the average patient using up to US\$100 000 of factor concentrate per year [2], and with limited accessibility to developing countries. The ability to bioengineer recombinant clotting factors with improved function holds promise to overcome some of the limitations in current treatment, the high costs 
of therapy and increase availability to a broader world haemophilia population $[3,4]$. Most research has been directed at overcoming the inherent limitations of rFVIII expression, and includes techniques to improve rFVIII biosynthesis and secretion, functional activity, half-life and antigenicity/immunogenicity (Table 1). Some of these molecules have already reached commercialization and have been used in gene-therapy strategies, while others are being evaluated in preclinical studies. Forms of rFIX with improved functional properties, such as more efficient expression and higher specific activity, have been investigated in preclinical studies and may also prove useful in gene-therapy trials for haemophilia B (Table 1) (reviewed in [5]).

With each strategy, the research approach used has been, firstly, to understand the limitations in rFVIII properties and its impact on production and therapy. Next, key functional regions of the protein are mapped or better characterized, and then targeted bioengineering strategies are applied to alter the properties of that particular rFVIII. This review will summarize three examples of the application of this approach.

The best example of a bioengineered molecule to proceed all the way through these phases is the development of B-domain deleted (BDD)-FVIII. Early on in the study of rFVIII expression, it was demonstrated that the $\mathrm{B}$ domain of FVIII, the equivalent of approximately $38 \%$ of the primary cDNA sequence, could be removed without loss of FVIII procoagulant activity. This significantly improved the yield of rFVIII [6,7]. The increased expression resulted from markedly increased levels of mRNA and increased translation. The reduced size of the BDD-FVIII cDNA facilitated packaging within certain viral vectors. As BDD-FVIII has a biochemical profile similar to wild-type FVIII $[7,8]$, there was enthusiasm to adopt it for gene-therapy strategies. Clinical studies had already shown that BDD-FVIII provided safe, well-tolerated and effective treatment for haemophilia A [9]. Most significantly, rates of inhibitor formation in previously untreated patients with haemophilia A were similar to that observed with full-length rFVIII concentrates [10], demonstrating that, despite such a major modification of the FVIII protein, this bioengineered form of FVIII was not more immunogenic. In another strategy, a truncated intron-1 sequence of FIX was inserted into BDD-FVIII cDNA in place of either FVIII introns 1,12 or 13 [11]. This led to an increase in FVIII secretion that

Table 1. Summary of bioengineering strategies for FVIII and FIX with improved functional properties

\begin{tabular}{|c|c|c|}
\hline $\begin{array}{l}\text { Targeted functional } \\
\text { improvement }\end{array}$ & $\begin{array}{l}\text { Bioengineering } \\
\text { strategy }\end{array}$ & References \\
\hline \multicolumn{3}{|l|}{ FVIII } \\
\hline \multicolumn{3}{|l|}{ Biosynthesis and secretion } \\
\hline \multirow[t]{2}{*}{ Increased mRNA expression } & Removal of entire B domain & {$[6,7,8]$} \\
\hline & Substitution with FIX intron 1 & {$[10]$} \\
\hline Reduced ER chaperone interactions & Phe309Ser & [15] \\
\hline Improved ER-Golgi transport & Short B domain containing variants & [17] \\
\hline \multicolumn{3}{|l|}{ Improved functional activity } \\
\hline Increased activation & des-(868-1562)-FVIII-HCII & [4] \\
\hline \multirow[t]{2}{*}{ Resistance to inactivation } & $\begin{array}{l}\text { Inactivation-resistant FVIII (IR8) (Arg336Ile/Arg562Lys/ } \\
\text { Arg740Ala/des-794-1689) }\end{array}$ & {$[20,21]$} \\
\hline & $\begin{array}{l}\text { A2-A3 disulphide-bridged } \\
\text { FVIII (Cys664-Cys1826) }\end{array}$ & {$[22]$} \\
\hline \multirow[t]{2}{*}{ Improved plasma half-life } & LRP-binding site mutations (A2 domain residues $484-509$ and $\mathrm{C} 2$ domain) & {$[4,12]$} \\
\hline & $\begin{array}{l}\text { Heparan sulphate proteoglycans-binding site mutations (A2 domain } \\
\text { residues 558-565) }\end{array}$ & 4,12 \\
\hline Reduced antigenicity & Porcine-human hybrids & [4] \\
\hline \multicolumn{3}{|l|}{ FIX } \\
\hline \multicolumn{3}{|l|}{ Biosynthesis and secretion } \\
\hline \multirow[t]{3}{*}{ Increased mRNA expression } & ATG triplets as translation initiation & \\
\hline & Truncated & \\
\hline & FIX intron 1 & \\
\hline Reduced collagen IV binding & Lys5Ala, Val10Lys & \\
\hline \multicolumn{3}{|l|}{ Improved functional activity } \\
\hline \multirow[t]{2}{*}{ Increased specific activity } & Arg338Ala & \\
\hline & FIX-FX hybrids & \\
\hline
\end{tabular}


was associated with a dramatically higher level of FVIII mRNA accumulation in the cell. More recently, investigators have gained insights into mechanisms that limit rFVIII expression including: (i) inefficient expression of FVIII mRNA; (ii) inefficient folding of the primary translation product within the endoplasmic reticulum (ER) with retention by chaperone proteins; and (iii) a requirement for facilitated transport from the ER to the Golgi apparatus (reviewed in Kaufman et al. [12] and Soukharev et al. [13]). By understanding the cellular mechanisms and mapping the key regions of FVIII, bioengineering strategies have been able to overcome each of these limitations, and improve the expression and secretion efficiency of FVIII. Strategies have included deletion of all or a significant portion of the $\mathrm{B}$ domain to improve mRNA yield $[7,14]$.

The second approach has involved a hydrophobic region of the A1 domain of FVIII, mapped as a putative binding site for immunoglobulin-binding protein (BiP) [15], a protein chaperone within the secretion pathway known to bind and retain FVIII within the ER. Targeted point mutations within the A1 domain identified conservative mutations (e.g. Phe309Ser) that could be introduced, leading to increased FVIII secretion efficiency [16]. In addition, a facilitated transport system that includes a protein complex (LMAN1/CFD2), which targets glycoprotein cargo into secretion vesicles moving from the ER to the Golgi was identified. This protein complex appears to interact with its cargo primarily through interaction with mannose residues on asparagine (N)-linked oligosaccharides [17]. The majority of the N-linked oligosaccharides within FVIII are clustered within the $\mathrm{B}$ domain. The addition of even a small portion of native FVIII B domain (optimally 226 amino acids with six $\mathrm{N}$-linked oligosaccharides, 226aa/N6) to BDD-FVIII produced a 5-10 fold higher secretion efficiency compared with BDD-FVIII [18]. When the Phe309Ser mutation was introduced into $226 \mathrm{aa} / \mathrm{N6}$, there was an additive effect, boosting secretion efficiency by up to 25 -fold compared with BDD-FVIII. The observations were similar when these novel FVIII constructs were synthesized in vivo within the haemophilia A mouse model. Thus these types of modifications could increase the efficiency of current commercial rFVIII production, could be applied to produce rFVIII within transgenic animals, and could increase the success of gene therapy applications.

Lastly, for many years it has been recognized that the thrombin-activated form of FVIII (FVIIIa) is a heterotrimer of subunits A1 and A2 and a thrombin-cleaved light chain. This heterotrimer is unstable and subject to spontaneous decay of its procoagulant activity, attributable to dissociation of its A2 subunit, which occurs at physiological $\mathrm{pH}$. In addition, recent studies have also shown that mutations in FVIII that decrease the stability of the FVIIIa heterotrimer result in haemophilia A $[19,20]$. Therefore, as A2 subunit dissociation limits procoagulant activity in vivo, investigators have attempted to stabilize the activated form of FVIIIa to enhance and prolong its procoagulant activity. An inactivation-resistant FVIII (IR8) was engineered, which retains the A2 domain covalently attached to the light chain, thus preventing its spontaneous dissociation [21]. Additionally, missense mutations at activated protein $\mathrm{C}$ inactivation cleavage sites provided resistance to further proteolysis of FVIIIa. In vitro, this molecule demonstrated stability of activity following thrombin activation and had a markedly higher specific activity. Recent preclinical studies within the haemophilia A mouse model demonstrated that IR8 provided more efficient haemostasis than rFVIII at significantly lower doses of protein infused [22]. Despite its higher specific activity and stability, it was not observed to be more thrombogenic in a carotid artery injury model within the haemophilia A mouse model. In another strategy, cysteines were substituted at residues 664 and 1826 within FVIII, successfully engineering a disulphide bond between the FVIII A2 and A3 domains to stabilize FVIIIa [23]. Following thrombin activation, the mutant lost only $20 \%$ of its peak activity after $40 \mathrm{~min}$ at $22{ }^{\circ} \mathrm{C}$ as measured by one-stage clotting assay. During this same incubation time, wild-type FVIIIa had lost more than $99 \%$ of its activity. FVIII proteins with prolonged activity following thrombin activation have the potential of increasing the efficacy of FVIII in plasma. It is possible that they may correct haemostasis in vivo at lower levels of protein, prolonging the activity of FVIIIa even when FVIII in plasma is present in levels usually ineffective for haemostasis. For other examples of bioengineering strategies for clotting factors, see recent reviews $[4,13]$.

\section{Advanced strategies for inhibitor management}

The question of inhibitors to FVIII has continued to baffle both clinicians and basic scientists, justifying the intense effort devoted to the design of new therapeutic approaches to either prevent or suppress FVIII-specific antibody formation. 
Recent progress made in understanding the mechanisms by which an immune response is elicited and maintained has permitted delineation of a number of potential non-antigen-specific strategies for the control of FVIII inhibitors, such as the use of antibodies to CD40L, B7 molecules or the CD20 B-cell surface marker. Results of such approaches have brought about much disillusion, attributable to two main causes: (i) FVIII is a large molecule and we are far from understanding how an immune response to it is elicited, especially with regard to the hierarchy of T-cell epitopes; and (ii) the immune response to FVIII is highly differentiated, including high-affinity antibodies with high rate of somatic mutations and (as extrapolated from observations made in the haemophilia A mouse model) efficient memorization. In fact, this situation might represent the worst scenario for a non-antigen-specific therapeutic approach.

Antigen-specific strategies are much more appealing, in order to prevent any detrimental side-effect on the immune reactivity of patients, who often already experience some degree of immunosuppression. There are basically three possible methods to achieve an antigen-specific down regulation: make use of antigen and its derivatives, target specific B cells or target specific T cells.

Targeting $\mathrm{T}$ cells would be very attractive, but, as stated above, we do not yet know enough about $\mathrm{T}$ cells. A number of key questions are now being addressed in specialized laboratories to determine how and when tolerance to FVIII is established, both centrally and in the periphery, and whether the T-cell response is amenable to suppression either directly or indirectly, through, for instance, regulatory $\mathrm{T}$ cells.

Using the antigen itself or some of its derivatives is under way. Possibly the best example of this so far is the use of mutant FVIII molecules in which inhibitorbinding epitopes have been altered to prevent antibody binding, as reported elsewhere.

Choosing B cells as targets for the therapy of inhibitors carries one main advantage, resulting from the high specificity and affinity of the B-cell receptor (BCR) itself. In addition, recent work on signal transduction after ligand binding [24] has demonstrated that several possibilities by which B cells can be anergized or even undergo apoptosis exist. However, a number of obstacles remain to be surmounted before a BCR-orientated therapy can be launched: (i) the B-cell pool is continuously replenished over the entire lifespan, which could render even sophisticated strategies only temporarily successful; (ii) memorization at the B-cell level makes anergy induction potentially fragile, as even non-specific events such as infection can activate memory B cells and drive them towards plasmocyte differentiation; and (iii) antibody-secreting plasmocytes located in the bone marrow essentially downregulate surface expression of a number of receptors and survive there for long periods of time.

Notwithstanding this, we are exploring the possibilities of controlling FVIII inhibitors by neutralizing both their inhibitory activity and production. Our studies are centred on the use of anti-idiotypic antibodies and were initiated on the basis of a number of observations. Firstly, conventional immune tolerance induction by infusion of large amounts of FVIII is known to be associated with induction of anti-idiotypic antibodies [25]. Secondly, clonal analysis of anti-FVIII human antibodies has shown that, at least for antibodies towards the $\mathrm{C} 2$ domain, a restricted number of $\mathrm{VH}$ families are used, thereby potentially reducing the diversity of the antiidiotypic immune response [26]. Thirdly, infusion of pools of immunoglobulins, known to contain antiidiotypic antibodies, results in successful neutralization of inhibitors, at least in the acquired form of haemophilia A [27].

A number of human monoclonal antibodies with inhibitory properties on FVIII function, and derived from the natural repertoire of patients' B memory cells [28], have been used to generate anti-idiotypic antibodies. The first of these anti-FVIII antibodies, BO2C11, has been fully characterized up to its crystal structure in combination with the $\mathrm{C} 2$ domain [29]. It recognizes the phospholipid-binding site of C2. Mouse anti-idiotypic antibodies to $\mathrm{BO} 2 \mathrm{C} 11$ are not only capable of neutralizing the inhibitory activity of the antibody in vitro, but show very significant neutralization of FVIII activity in haemophilia A mice reconstituted with FVIII and $\mathrm{BO} 2 \mathrm{C} 11$ [30]. Interestingly, the binding affinity of anti-idiotypic antibodies to $\mathrm{BO} 2 \mathrm{C} 11$ is comparable to the binding of BO2C11 to FVIII. Thus, a 50\% neutralization of FVIII inhibitory activity is obtained by equimolar concentrations of $\mathrm{BO} 2 \mathrm{C} 11$ and its corresponding anti-idiotypic antibody (mAb14C12). Experiments carried out with anti-FVIII inhibitors from unrelated patients showed that the idiotype recognized by mAb14C12 was expressed on specific antibodies of $\sim 50 \%$ of patients with anti-C2 inhibitors. This raises hope that some anti-idiotypic reagents will show broad cross-reactivity between patients.

Anti-idiotypic antibodies have the potential to downregulate the function of the B-cell clones expressing the corresponding idiotype, more than 
a mere neutralization of circulating inhibitors. Experiments are now ongoing to determine whether engineered antibody molecules could be of use to target, anergize and possibly induce apoptosis of $\mathrm{B}$ cells carrying the corresponding idiotype. Preliminary experiments indicate that anti-idiotypic antibodies to anti-A2 inhibitory antibodies could share the same properties. We are confident that this approach will lead to a valuable adjunct to the therapy of patients with inhibitors, alone or in combination with other forms of therapy.

An alternative, though complementary, approach has also been followed, which makes use of peptidic mimotopes derived from filamentous-phage display libraries [31]. Such short peptides are interesting in so far as they bind to the paratope of inhibitory antibodies in a highly specific manner. These mimotopes can be designed to differ significantly from the sequence and/or conformation of the FVIII region recognized by antibodies and, as such, have little chance to interfere with FVIII function. Both in vitro, and in vivo in the haemophilia A mouse model reconstituted with human rFVIII, such mimotopes have been shown to successfully neutralize inhibitors. Assuming that increased half-life of such peptides can be obtained in vivo by making use, for instance, of $\mathrm{D}$-amino acids or retro-inverso modification, this therapeutic strategy could be of help in emergency situations, such as prior to surgery.

\section{Correction of haemophilia A using RNA repair}

The development of molecular repair strategies has traditionally been viewed as repair of DNA mutations through DNA recombination. Although progress continues in this area of research, the level of DNA repair is low and typically requires a selection step to retrieve corrected cells. Here we describe a novel approach to correct genetic diseases at the pre-messenger RNA level through the use of spliceosome-mediated RNA trans-splicing. Despite relatively modest levels of repair at the RNA level and in the absence of selection, in vivo repair of genetic defects is achieved. Trans-splicing offers distinct advantages over conventional gene therapy and in vivo proof of principle has been demonstrated for haemophilia A.

\section{RNA cis-splicing}

The transcription of genes generates precursor messenger RNAs (pre-mRNAs) that contain exons and introns. The introns are removed from the
pre-mRNA and the adjacent exons are ligated together in a highly orchestrated fashion to form mature meRNA (Fig. 1A). This process, which occurs within one pre-mRNA, is often called premRNA cis-splicing and is catalysed by the spliceosome [32], an enzymatic complex. The exon-intron boundaries of pre-mRNA recognized by the spliceosome are defined by four conserved cis-elements, which include: (i) the $5^{\prime}$ splice site; (ii) the $3^{\prime}$ splice site; (iii) the branchpoint; and (iv) the polypyrimidine tract (Fig. 1B). The $5^{\prime}$ splice site consensus sequence of U2 introns is AGIGURAGU (where I is the exon-intron junction). The $3^{\prime}$ end of the intron contains the branchpoint, which is poorly conserved in mammals, with a consensus sequence of YNYURAC (the underlined A is termed the branchpoint), a polypyrimidine tract, which is highly conserved in mammals, and the $3^{\prime}$ splice site with a consensus of YAG|G.

\section{RNA trans-splicing}

A second and less well-known form of natural RNA splicing is called trans-splicing, which occurs between two independently transcribed RNA precursors to form composite mRNA (Fig. 1C). Several disparate forms of trans-splicing have been

(a)

Cis-splicing Splicing within a single pre-mRNA:

)

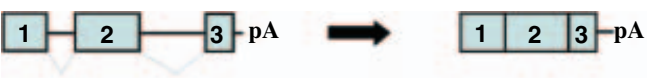

(b)

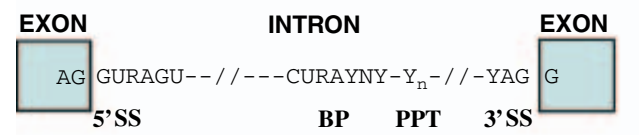

Trans-splicing Splicing between more than one pre-mRNA:

(c)

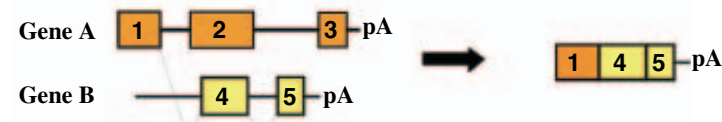

Fig. 1. Schematic diagram showing two different pathways of premRNA splicing in eukaryotes. (a) The process of cis-splicing. A single pre-mRNA here containing three exons $(1,2,3)$ and two introns are spliced together to form mature mRNA. (b) Idealized structure of a eukaryotic U2 intron showing the four cis-elements that are responsible for defining the intron-exon boundaries of the intron. (c) The process of trans-splicing. Exon 1 of the pre-mRNA from gene $\mathrm{A}$ is shown splicing to exon 4 of the pre-mRNA from gene $\mathrm{B}$. The product of the reaction is a composite message consisting of exon 1 from gene A plus exons 4 and 5 from gene B. Both processes (cis and trans) are mediated by the spliceosome. BP, branchpoint; pA, poly A signal; PPT, polypyrimidine tract; SS, splice site. 
described in species spanning different kingdoms, but in mammalian cells, trans-splicing is considered to be rare compared with cis-splicing. However, the growing list of genes that undergo trans-splicing, together with a recent computational study showing that some sequences in public databases may be the product of trans-splicing [33], suggests that many more examples will be discovered.

The ability of mammalian cells to perform RNA trans-splicing, which was first shown in 1992 [34], offers the opportunity to alter gene expression at the RNA level for therapeutic intervention [35]. One method of trans-splicing using engineered molecules, termed spliceosome-mediated RNA trans-splicing (SMaRT), has been described, which is capable of reprogramming RNA in mammalian cells [36] (Fig. 2). SMaRT uses specialized constructs called pre-trans-splicing molecules (PTMs) that are engineered to bind specific pre-mRNAs in the nucleus and effect a trans-splicing event between the target RNA and PTM mediated by the spliceosome. Prototype PTMs comprise three domains (Fig. 3): (i) a binding domain that is complementary to the target intron and serves to tether the PTM to a specific location within the target; (ii) a splicing domain, which contains splicing elements that are equivalent to those found in cis-splicing precursors; and (iii) a coding domain, consisting of an exon or exons that are trans-spliced to the target. The binding domain and $c i s$-splicing elements are not retained in the final modified RNA product. The splicing domain is

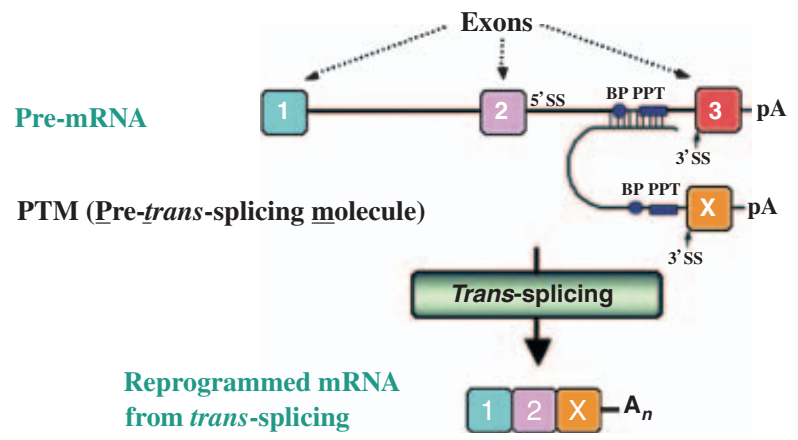

Fig. 2. Schematic diagram of the process of spliceosome-mediated RNA trans-splicing (SMaRT). A pre-trans-splicing molecule is shown binding to the $3^{\prime}$ splice site an intron in the pre-mRNA target. A trans-splicing reaction between the $5^{\prime}$ splice site adjacent to exon 2 of the target and the 3' splice site of the PTM results in a composite mRNA consisting of exons $1-2$ plus coding $\mathrm{X}$. This process can be made to occur at any exon-intron junction in the target. BP, branchpoint; pA, poly A signal; PPT, polypyrimidine tract; SS, splice site.

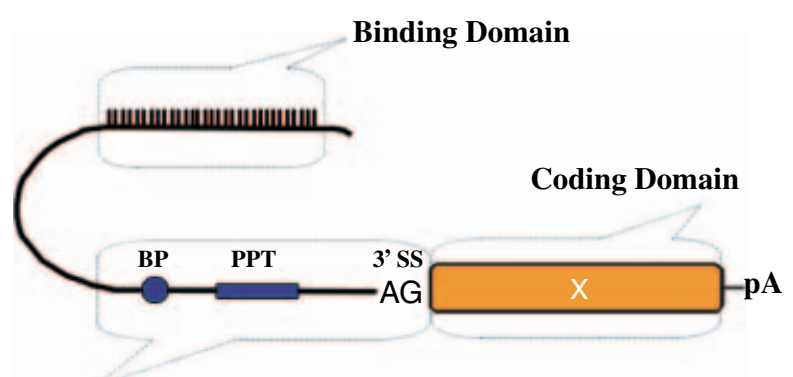

Splice Elements

Fig. 3. Diagram of a pre-trans-splicing molecule (PTM). The three main domains in the PTM are a binding domain, a set of splice elements and a coding unit (X). The sequence between the binding domain and splice elements is termed a spacer sequence; this is not absolutely required for efficient trans-splicing. PTMs can be expressed using any gene delivery system. BP, branchpoint; pA, poly A signal; PPT, polypyrimidine tract; SS, splice site.

designed to maximize trans-splicing activity and therefore typically contains a potent branchpoint sequence (UACUAAC), and a long pyrimidine-rich tract. A typical binding-domain size is $70-150$ bases [37]. The coding sequence can be one or more exons, a complete coding sequence, or a genomic fragment. SMaRT reactions result in the simultaneous introduction and removal of RNA sequence from the target pre-mRNA. As is true for all forms of SMaRT repair, each PTM need only deliver the defective portion of the transgene, as opposed to the entire gene in conventional gene replacement [38]. The choice of PTM type for any one application (see below) may be driven by such factors as target RNA level, type of target, level of conversion required, or the region of the target that requires modification.

\section{RNA splicing can correct haemophilia A}

SMaRT offers several advantages over conventional gene therapy: (i) reduction of transgene size, as only a fragment of the gene is used, allowing application to large disease genes such as the FVIII gene (ii) endogenous regulation of the repaired gene, as the repaired transcript should have the same spatial and temporal expression pattern as the endogenous target; (iii) the ability to generate mRNA of normal length; (iv) a much broader choice of regulatory sequences; and ( $\mathrm{v}$ ) elimination of ectopic expression of the transgene because RNA repair is dependent on the presence of the target.

The usefulness of SMaRT as an RNA-repair technology has been proven in a variety of models in vitro, ex vivo and in vivo. Early research clearly 
Fig. 4. Trans-splicing approach to repair of the mouse FVIII exon 16 mutation. The schematic diagram shows a mouse FVIII PTM (coding for exons 16-26) binding to intron 15 in a mutant pre-mRNA target. A trans-splicing event between exon 15 of the target and exon 16 of the PTM generates a full length repaired mRNA. Note that structure of the mouse gene is based on the known genomic structure of the human FVIII gene. BP, branchpoint; pA, poly A signal; PPT, polypyrimidine tract; SS, splice site.

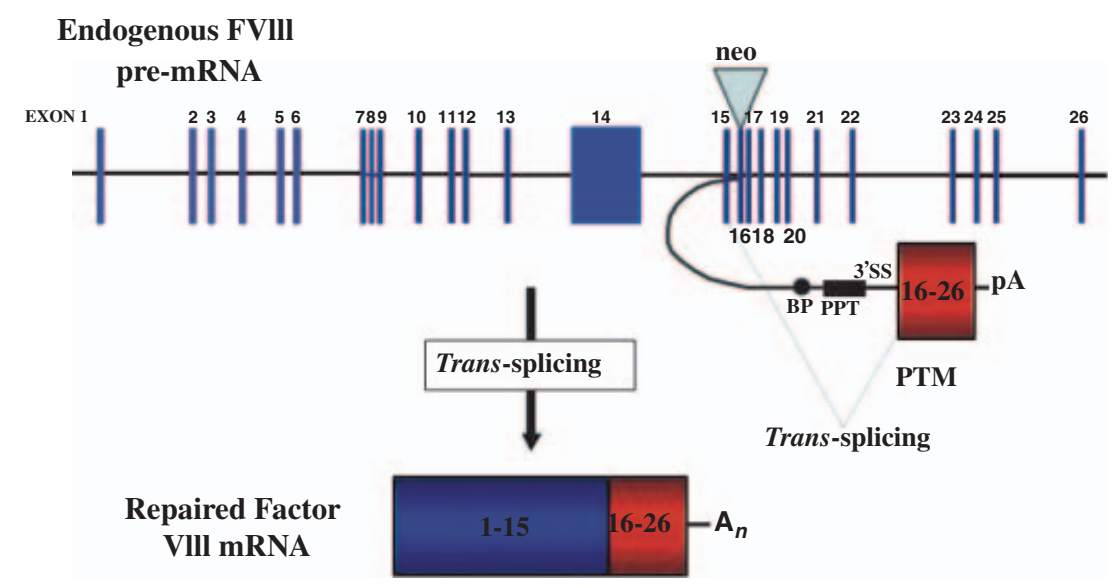

Endogenous FVIII pre-mRNA established that RNA repair by SMaRT was feasible in mammalian tissue-culture cells and that the level of repair was significantly higher than was originally anticipated $[36,37,39]$. The first in vivo demonstration of SMaRT was performed in FVIII haemophilia A knockout mice [40], which were created by insertion of the neomycin resistance gene in exon 16 of the mouse FVIII gene (F8 E16 knockout mice) [41]; no functional FVIII protein is detected in these animals due to the absence of FVIII light chains. For this study, a PTM was designed to trans-splice to exon 15 of the endogenous FVIII pre-mRNA target (just upstream of the exon 16 disruption) and replace the coding sequence for exons 16-26 (Fig. 4). This study demonstrated the presence of repaired FVIII mRNA in the liver of PTM-treated mice, the presence of circulating FVIII protein, and FVIII activity at up to $25 \%$ of normal over a study period of 8 weeks. Finally, haemostatic challenge of F8 E16 mice showed that animals that received a repair PTM survived a tail clip, whereas all naïve F8 E16 knockout mice or all knockout mice that received a mutated PTM (trans-splicing incompetent) did not survive.

\section{Future directions}

RNA therapy using SMaRT represents an entirely new approach to gene therapy, offering the opportunity to invade an endogenous mutant pre-mRNA in the nucleus of a diseased cell, precisely excise the mutated region responsible for the disease and replace it with a normal coding sequence. This approach has many advantages compared with existing conventional gene replacement. SMaRT coupled with recent advances in viral vectors will likely offer new therapeutic potential for many genetic and acquired disorders.

\section{Acknowledgements}

SWP and CEW wish to acknoweldge funding by NHLBI of National Institutes of Health and the National Haemophilia Foundation.

\section{References}

1 Mitterer A, Mundt W, Bjornson E, Dorner F. Development of an advanced category recombinant FVIII, anti-hemophilic factor (recombinant) plasma/albuminfree method (rAHF-PFM). J Thromb Haemost 2003; 1: 1652.

2 Bohn RL, Avorn J, Glynn RJ, Choodnovskiy I, Haschemeyer R, Aledort LM. Prophylactic use of factor VIII: an economic evaluation. Thromb Haemost 1998; 79: 932-7.

3 Saenko EL, Ananyeva NM, Moayeri M, Ramezani A, Hawley RG. Development of improved factor VIII molecules and new gene transfer approaches for hemophilia A. Curr Gene Ther 2003; 3: 2741.

4 Saenko EL, Ananyeva NM, Shima M, Hauser CA, Pipe $\mathrm{SW}$. The future of recombinant coagulation factors. J Thromb Haemost 2003; 1: 922-30.

5 Pipe SW. Coagulation factors with improved properties for hemophilia gene therapy. Semin Thromb Hemost 2004; 30: 227-37.

6 Toole JJ, Pittman DD, Orr EC, Murtha P, Wasley LC, Kaufman RJ. A large region (approximately equal to $95 \mathrm{kDa}$ ) of human factor VIII is dispensable for in vitro procoagulant activity. Proc Natl Acad Sci USA 1986; 83: 5939-42.

7 Pittman DD, Alderman EM, Tomkinson KN, Wang JH, Giles AR, Kaufman RJ. Biochemical, immunological, and in vivo functional characterization of B-domain-deleted factor VIII. Blood 1993; 81: 292535.

8 Sandberg H, Almstedt A, Brandt J et al. Structural and functional characteristics of the B-domain-deleted 
recombinant factor VIII protein, r-VIII SQ. Thromb Haemost 2001; 85: 93-100.

9 Courter SG, Bedrosian CL. Clinical evaluation of B-domain deleted recombinant factor VIII in previously treated patients. Semin Hematol 2001; 38: 44-51.

10 Courter SG, Bedrosian CL. Clinical evaluation of B-domain deleted recombinant factor VIII in previously untreated patients. Semin Hematol 2001; 38: 52-9.

11 Plantier JL, Rodriguez MH, Enjolras N, Attali O, Negrier C. A factor VIII minigene comprising the truncated intron I of factor IX highly improves the in vitro production of factor VIII. Thromb Haemost 2001; 86: 596-603.

12 Kaufman RJ, Pipe SW, Tagliavacca L, Swaroop M, Moussalli M. Biosynthesis, assembly and secretion of coagulation factor VIII. Blood Coagul Fibrinolysis 1997; 8 (Suppl. 2): S3-14.

13 Soukharev S, Hammond D, Ananyeva NM et al. Expression of factor VIII in recombinant and transgenic systems. Blood Cells Mol Dis 2002; 28: 234-48.

14 Pittman DD, Marquette KA, Kaufman RJ. Role of the $\mathrm{B}$ domain for factor VIII and factor V expression and function. Blood 1994; 84: 4214-25.

15 Marquette KA, Pittman DD, Kaufman RJ. A 110amino acid region within the A1-domain of coagulation factor VIII inhibits secretion from mammalian cells. J Biol Chem 1995; 270: 10297-303.

16 Swaroop M, Moussalli M, Pipe SW, Kaufman RJ. Mutagenesis of a potential immunoglobulin-binding protein-binding site enhances secretion of coagulation factor VIII. J Biol Chem 1997; 272: 24121-4.

17 Cunningham MA, Pipe SW, Zhang B, Hauri H-P, Ginsburg D, Kaufman RJ. LMAN1 is a molecular chaperone for the secretion of coagulation factor VIII. J Thromb Haemost 2003; 1: 2360-7.

18 Miao HZ, Sirachainan N, Palmer L et al. Bioengineering of coagulation factor VIII for improved secretion. Blood 2004; 103: 3412-9.

19 Pipe SW, Saenko EL, Eickhorst AN, Kemball-Cook G, Kaufman RJ. Hemophilia A mutations associated with 1-stage/2-stage activity discrepancy disrupt proteinprotein interactions within the triplicated A domains of thrombin-activated factor VIIIa. Blood 2001; 97: 68591.

20 Hakeos WH, Miao H, Sirachainan N et al. Hemophilia A mutations within the factor VIII, A2-A3 subunit interface destabilize factor VIIIa and cause one-stage/ two-stage activity discrepancy. Thromb Haemost 2002; 88: 781-7.

21 Pipe SW, Kaufman RJ. Characterization of a genetically engineered inactivation-resistant coagulation factor VIIIa. Proc Natl Acad Sci USA 1997; 94: 11851-6.

22 Thornburg CD, Palmer L, Miao HZ, Deng X, Kaufman RJ, Pipe SW. Inactivation-resistant factor VIII provides superior hemostasis to wild-type factor VIII in a murine hemophilia A model without increased thrombogenicity. Blood 2003; 102: 299a.
23 Gale AJ, Pellequer JL, Griffin JH. A novel engineered interdomain disulfide bond stabilizes human blood coagulation factor VIIIa. J Thromb Haemost 2003; 1: OC094.

24 Vilen BJ, Nakamura T, Cambier JC. Antigen-stimulated dissociation of BCR $\mathrm{mIg}$ from Ig-alpha/Ig-beta: implications for receptor desensitization. Immunity 1999; 10: 239-48.

25 Gilles JG, Desqueper B, Lenk H, Vermylen J, SaintRemy JM. Neutralizing antiidiotypic antibodies to factor VIII inhibitors after desensitization in patients with hemophilia A. J Clin Invest 1996; 97: 1382-8.

26 van den Brink EN, Bril WS, Turenhout EA et al. Two classes of germline genes both derived from the $\mathrm{V}(\mathrm{H}) 1$ family direct the formation of human antibodies that recognize distinct antigenic sites in the $\mathrm{C} 2$ domain of factor VIII. Blood 2002; 99: 2828-34.

27 Dietrich G, Algiman M, Sultan Y, Nydegger UE, Kazatchkine MD. Origin of anti-idiotypic activity against anti-factor VIII autoantibodies in pools of normal human immunoglobulin G (IVIg). Blood 1992; 79: 2946-51.

28 Jacquemin MG, Desqueper BG, Benhida A et al. Mechanism and kinetics of factor VIII inactivation: study with an IgG4 monoclonal antibody derived from a hemophilia A patient with inhibitor. Blood 1998; 92: 496-506.

29 Spiegel PC Jr, Jacquemin M, Saint-Remy JM, Stoddard BL, Pratt KP. Structure of a factor VIII, C2 domainimmunoglobulin G4kappa Fab complex: identification of an inhibitory antibody epitope on the surface of factor VIII. Blood 2001; 98: 13-9.

30 Gilles JG, Grailly SC, De Maeyer M, Jacquemin MG, VanderElst LP, Saint-Remy JM. In vivo neutralization of a C2 domain-specific human anti-factor VIII inhibitor by an anti-idiotypic antibody. Blood 2004; 103: 2617-23.

31 Villard S, Lacroix-Desmazes S, Kieber-Emmons T et al. Peptide decoys selected by phage display block in vitro and in vivo activity of a human anti-FVIII inhibitor. Blood 2003; 102: 949-52.

32 Burge C, Tuschi T, Sharp P. Splicing of precursors to $m R N A s$ by the spicesome. Cold Spring Harbor: Cold Spring Harbor Laboratory Press, 1999.

33 Romani A, Guerra E, Trerotola M, Alberti S. Detection and analysis of spliced chimeric mRNAs in sequence databanks. Nucleic Acids Res 2003; 31: e17.

34 Bruzik JP, Maniatis T. Spliced leader RNAs from lower eukaryotes are trans-spliced in mammalian cells. Nature 1992; 360: 692-5.

35 Sullenger BA, Gilboa E. Emerging clinical applications of RNA. Nature 2002; 418: 252-8.

36 Puttaraju M, Jamison SF, Mansfield SG, Garcia-Blanco MA, Mitchell LG. Spliceosome-mediated RNA transsplicing as a tool for gene therapy. Nat Biotechnol 1999; 17: 246-52.

37 Puttaraju M, DiPasquale J, Baker CC, Mitchell LG, Garcia-Blanco MA. Messenger RNA repair and 
restoration of protein function by spliceosome-mediated RNA trans-splicing. Mol Ther 2001; 4: 105-14.

38 Garcia-Blanco MA. Messenger RNA reprogramming by spliceosome-mediated RNA trans-splicing. J Clin Invest 2003; 112: 474-80.

39 Mansfield SG, Kole J, Puttaraju M et al. Repair of CFTR mRNA by spliceosome-mediated RNA transsplicing. Gene Ther 2000; 7: 1885-95.
40 Chao H, Mansfield SG, Bartel RC et al. Phenotype correction of hemophilia A mice by spliceosomemediated RNA trans-splicing. Nat Med 2003; 9: 1015-9.

41 Bi L, Lawler AM, Antonarakis SE, High KA, Gearhart JD, Kazazian HH Jr. Targeted disruption of the mouse factor VIII gene produces a model of haemophilia A. Nat Genet 1995; 10: 119-21. 